\title{
Preeclamptic cord blood hemolysis and the effect of Monascus purpureus and Saccharomyces cerevisiae in modulating preeclamptic stress
}

\author{
Ekambaram $\mathrm{P}^{1}$, Jayachandran $\mathrm{T}^{1}$, Venkatraman $\mathrm{U}^{1}$, Leonard $\mathrm{S}^{2}$ \\ P.G. Department of Biochemistry, Bharathi Women's College, Affiliated to University of Madras, Chennai, \\ Tamilnadu, India. dstpadmini@rediffmail.com
}

\begin{abstract}
Background: Preeclampsia is associated with impaired antioxidant defense that results in maternofetal complications. In addition to antioxidant deficiency, hemolytic disorder has also been observed in preeclamptic mother.

Methods: This study aims in analyzing the fetal complications using cord blood RBC (red blood cell); further the antihemolytic and antioxidant efficiency of two common probiotic yeasts Monascus purpureus and Saccharomyces cerevisiae in preeclamptic and normotensive RBCs were assessed.

Results: There was a significant decrease in the antioxidant status $(p<0.05)$ with increased oxidative stress, nitrative stress $(p<0.05)$ and hemolysis $(p<0.001)$ in preeclamptic RBC comparatively. M. purpureus demonstrated a highly significant reactive oxygen radical scavenging activity $(p<0.001)$ whereas $S$. cerevisiae exhibited a highly significant nitric oxide radical scavenging activity $(p<0.001)$. It was noted that oxidative stress hemolysis was decreased with increased antioxidant level in cord blood RBC from both samples after incubation with both yeasts in a similar manner. The antihemolytic property of $M$. purpureus and $S$. cerevisiae suggests that $S$. cerevisiae functions efficiently with increasing stress.

Conclusion: This study demonstrates for the first time that despite their differential scavenging activities, a diet rich in $M$. purpureus and $S$. cerevisiae could equally serve as a good natural supplement to alleviate the stress status in the preeclamptic fetus (Tab. 4, Fig. 1, Ref. 39). Full Text in PDF www.elis.sk.

Key words: Cord blood RBC, hemolysis, Monascus purpureus, Preeclampsia, Saccharomyces cerevisiae.
\end{abstract}

\begin{abstract}
Abbreviations: RBC - Red blood cell, HBSS - Hank's Balanced Salt Solution, HELLP - Hemolytic anemia Elevated Liver enzymes and Low Platelet count, DPPH - 2,2-diphenyl-1-picrylhydrazyl, MDA - Malondialdehyde, G6PDH - Glucose 6-phosphate dehydrogenase, $\mathrm{H}_{2} \mathrm{O}_{2}$ - Hydrogen peroxide, TAC - Toatal antioxidant capacity, ABTS 2, - 2'-azinobis-3-ethyl-benzothiozoline-6-sulphonic acid, ROS - Reactive oxygen species, RNS - Reactive nitrogen species, $\mathrm{NO}_{2}^{-}-$Nitrite, $\mathrm{NO}_{3}^{-}-$Nitrate, $\mathrm{IC}_{50}-$ half maximal inhibitory concentration, LPO - Lipid peroxide.
\end{abstract}

Preeclampsia is a pregnancy-specific condition characterized by hypertension and proteinuria that remits after delivery (1). It is a hypoxic condition (2), which can increase the number of RBC in cord blood (3). Umbilical cord blood RBCs (red blood cells) play a vital role in nourishing the fetus (3). The course of preeclamptic/eclamptic patients may be complicated by HELLP syndrome, syndrome of intravascular hemolysis $(\mathrm{H})$, elevated liver enzymes (EL) and low platelet count (LP) (4). A case of severe preeclampsia in which hemolysis and

${ }^{1}$ P.G. Department of Biochemistry, Bharathi Women's College, Affiliated to University of Madras, Chennai, Tamilnadu, India, and ${ }^{2}$ C.S.I Rainy Multispeciality Hospital, Chennai, Tamilnadu, India

Address for correspondence: E. Padmini, MD, Bharathi Women's College, Affiliated to University of Madras, Chennai - 600108, Tamilnadu, India. Phone: +91.044.26213748, Fax: +91.044.25280473 rapid platelet consumption persisted after delivery was noted in early 1985 (5). Hemolytic disorder like the HELLP syndrome has also been observed in preeclamptic mother in addition to antioxidant deficiency (6), but similar complication in fetus has not been observed.

Preeclamptic stress in the fetus and the corresponding fetal response are reflected in the cord blood. Oxidative stress increases during preeclampsia and results in increased production of lipid peroxides (LPO), reactive oxygen species (ROS) and superoxide anion radicals $(7,8)$. Antioxidants such as carotenoids, tocopherols, and ascorbic acid are lower in women with preeclampsia (9). In this context, this study was undertaken to determine the changes in cord blood levels of hemolysis, oxidative stress, nitrative stress and antioxidant levels of RBC in preeclamptic subjects compared to normotensive subjects; for analyzing the fetal complication along with its response to preeclampsia. Various natural alternative medicines have been suggested and utilized for controlling preeclampsia.

Yeast contains a system of antioxidant enzymes that protects them from oxidative injury. Monascus purpureus and Saccharomyces cerevisiae are two most common yeasts having nutritional and medicinal properties more often consumed on the Asian continent. M. purpureus is used as medicinal food to improve blood circulation. It is used to prepare fermented red yeast rice which is commonly consumed in many Asian countries $(10,11)$. Other applications for $M$. purpureus are that lovastatin and other statin drugs produced from this yeast may be useful for treating or pre- 
venting osteoporosis $(12,13)$. It contains Monacolin $\mathrm{K}$, known as lovastatin, which is a commonly prescribed lipid-lowering drug that significantly reduces high cholesterol. M. purpureus contains a large amount of GABA and possesses antihypertensive effects for humans (14). S. cerevisiae is alternatively regarded as nutritional yeast. $S$ cerevisiae is also found in many commonly consumed Asian food like Dosa, butter, curd, fruit juice and rice cakes (15). $S$. cerevisiae has been studied extensively as a dietary supplement due to the rich source of vitamins and minerals present in it (16). The antioxidant and anti-hemolytic potential of yeast extract was determined through scavenging assays and its ability to inhibit free radical formation through incubation studies with cord blood RBC.

\section{Materials and methods}

\section{Selection of sample}

About 20 patients with preeclampsia in the age group of $20-40$ years were included in the study as test subjects, and 20 normotensive pregnant women of similar age and race were included as control subjects. Patients with preeclampsia were defined on the basis of the following clinical and laboratory criteria (Tab. 1); systolic pressure $\geq 140 \mathrm{mmHg}$ and diastolic pressure $\geq 90 \mathrm{mmHg}$ noted at least on two occasions, proteinuria levels $\geq 300 \mathrm{mg} / \mathrm{dl}$ found at least in two random specimens. The control group women were without any maternal and fetal complication during their pregnancy period. There were 5 vaginal deliveries and 15 Caesarean sections in the test group, and 16 vaginal deliveries and 4 Caesarean sections in the control group.

\section{Collection of sample}

Immediately after the birth of the baby, the umbilical cord was clamped 8-10 inches away from the first clamp and the cord was

Tab. 1. Demographic data and clinical characteristics of the normotensive and preeclamptic subjects.

\begin{tabular}{lcc}
\hline Character & Control $(\mathrm{n}=20)$ & Test $(\mathrm{n}=20)$ \\
\hline Maternal age (years) & $24.7 \pm 2.7$ & $21.5 \pm 1.4$ \\
Gestational age at delivery (weeks) & $37.8 \pm 0.4$ & $60.8 \pm 4.8^{* *}$ \\
Pre pregnancy weight $(\mathrm{Kg})$ & $50.1 \pm 4.2$ & $60.8 \pm 4.8^{*}$ \\
Pregnancy weight $(\mathrm{Kg})$ & $54.3 \pm 7.6$ & $69.1 \pm 8.1^{*}$ \\
Pre pregnancy BP (mmHg) & & \\
$\quad$ Systolic & $112.5 \pm 6.2$ & $114.5 \pm 6.4^{\mathrm{NS}}$ \\
$\quad$ Diastolic & $77.2 \pm 5.4$ & $77.1 \pm 4.8^{\mathrm{NS}}$ \\
Pregnancy BP at 20 weeks (mmHg) & & \\
$\quad$ Systolic & $115.7 \pm 7.5$ & $138.4 \pm 4.1^{*}$ \\
$\quad$ Diastolic & $77.5 \pm 4.1$ & $100.52 \pm 9.2^{*}$ \\
Pregnancy BP at term (mmHg) & $120.6 \pm 8.0$ & $150.1 \pm 8.1^{*}$ \\
$\quad$ Systolic & $80.5 \pm 6.9$ & $109.2 \pm 7.1^{*}$ \\
Diastolic & $1.7 \pm 0.86$ & $1.3 \pm 0.51^{\mathrm{NS}}$ \\
Parity & & \\
Type of delivery & 16 & 5 \\
Vaginal & 4 & 15 \\
Caesarean & $3.35 \pm 0.25$ & $2.51 \pm 0.69^{*}$ \\
Infant birth weight & & \\
** p $<0.05$ when compared with RBC isolated from normotensive pregnant women \\
* p $<0.01$ when compared with RBC isolated from normotensive pregnant women \\
NS - not significant when compared with RBC isolated from normotensive preg- \\
nant women
\end{tabular}

cut to collect the cord blood. The blood was collected in a sterile heparin-coated vacutainer.

\section{Isolation of $R B C$}

An open syringe, filled with cord blood was closed at the tip, kept upright, and then centrifuged at $800 \mathrm{~g}$ for $20 \mathrm{~min}$ at $4{ }^{\circ} \mathrm{C}$ without the piston. The resulting plasma was discarded. After opening the syringe at the tip, about $2 / 3$ of RBC sediment was carefully allowed to drop out of the syringe and was used for further analysis. The isolated RBCs were confirmed by performing Glucose 6-phosphate dehydrogenase enzyme assay by the method of Noltmann et al. (17).

\section{Yeast preparation}

The white yeast culture was purchased from a private research laboratory, Chennai, India. The microorganism was maintained by sub-culturing in Potato Dextrose agar slants. The Microbial type culture collection strain (MTCC) of red yeast (MTCC No. 369), was purchased from Indian Institute of Microbial Technology, Chandigarh, India. The fungus was maintained by sub-culturing in potato dextrose agar plates.

\section{Incubation studies of $R B C$ with yeast}

$100 \mu \mathrm{l}$ of RBCs collected from normotensive and preeclamptic women were incubated with $1 \mathrm{~mL}$ of Hanks Balanced Salt Medium containing $5.5 \mathrm{mM}$ glucose (pH 7.4) for $24 \mathrm{~h}$ at $37^{\circ} \mathrm{C}$ in a shaking water bath. The RBCs were then incubated with $M$. purpureus and S. cerevisiae at appropriate concentration for $2 \mathrm{~h}$ at $37^{\circ} \mathrm{C}$. Control RBCs were maintained with an equal volume of HBSS (Hank's Balanced Salt Solution) for the same duration at $37^{\circ} \mathrm{C}$.

\section{$R B C$ hemolysis in vitro}

This was measured after addition of hydrogen peroxide $\left(\mathrm{H}_{2} \mathrm{O}_{2}\right)$ with a technique modified from that described by Horwitt et al (18). A volume of $0.1 \mathrm{~mL}$ of RBC was taken in four test tubes. The first tube treated with HBSS serves as a negative control. The second tube treated with $2 \% \mathrm{H}_{2} \mathrm{O}_{2}$ serves as the positive control. Tubes 3-4 were treated with $0.1 \mathrm{~mL}$ of $\mathrm{H}_{2} \mathrm{O}_{2}$ and $0.1 \mathrm{~mL}$ of test samples (RBC incubated with M. purpureus and $S$. cerevisiae). All the tubes were incubated at $37^{\circ} \mathrm{C}$ for $3 \mathrm{~h}$. All samples were centrifuged, and the absorbance of the supernatant was measured at $575 \mathrm{~nm}$ as an indication of the degree of hemolysis.

\section{Determination of antioxidant status of yeast}

The activity of catalase was estimated by the method of Beer et al (19). The enzyme activity was expressed as Units/mg protein. DPPH (2,2-diphenyl-1-picrylhydrazyl) radical scavenging ability was determined by the method of Viturro et al (20). Vitamin-C was used as a standard. Nitric oxide radical inhibition activity was determined by the method of Garrat (21). Rutin was used as a standard. Superoxide anion scavenging ability was measured by the method of Nagai et al (22). Curcumin was used as a positive control. Hydroxyl radical scavenging activity was determined by method of Halliwell et al (23). Vitamin E was used as a standard. The reducing power was determined according to the method de- 


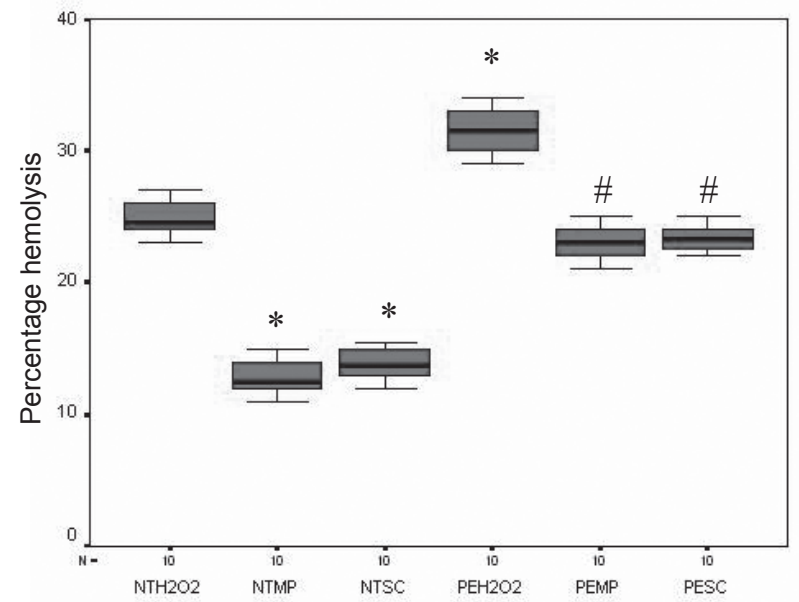

Fig. 1. $\mathrm{H}_{2} \mathrm{O}_{2}$-induced hemolysis of normotensive and preeclamptic cord blood RBC with $M$. purpureus and $S$. cerevisiae. ${ }^{*} \mathrm{p}<0.001$ when compared with $\mathrm{H}_{2} \mathrm{O}_{2}$ induced hemolysis of normotensive cord blood $\mathrm{RBC}, \# \mathbf{p}<0.001$ when compared with $\mathrm{H}_{2} \mathrm{O}_{2}$ induced hemolysis of preeclamptic cord blood RBC.

veloped by method of Oyaizu (24). Butylated hydroxy toluene was used as a standard. Total antioxidant capacity of yeast extracts was evaluated by the method of Erel (25). Gallic acid was used as a standard. Total phenolic content of yeast extract was determined by method of Chandler and Dodds (26). Gallic acid was used as a standard. The phyto-components present in the aqueous extract of $M$. purpureus and $S$. cerevisiae were identified by means of qualitative analysis.

\section{Determination of oxidative and nitrative stress}

The levels of LPO were determined by the method of Ohkawa et al (27). The LPO content was expressed as nanomoles of MDA (Malondialdehyde)/mg protein. Nitrite and nitrate were estimated by the method of Yokoi et al (28). The results were expressed as $\mu \mathrm{mol} / \mathrm{mg}$ protein.

\section{Determination of antioxidant status in RBC after incubation}

The activity of catalase was estimated by the method of Beer et al(19). The enzyme activity was expressed as Units/mg protein. Total antioxidant capacity of the yeast extracts was evaluated by the method of Erel (25).

\section{Statistical analysis}

Data were analyzed using statistical software package. Student's t-test, Two-way ANOVA was used to ascertain the significance of variations between normotensive and preeclamptic pregnant women. All data were presented as mean \pm SD of 20 subject samples. Differences were considered significant at $\mathrm{p}<0.05$, $\mathrm{p}<0.001$. The hemolytic activity was expressed as medians for better comparative analysis. Further a Spearman rank correlation was performed to the results obtained for the anti-hemolytic activity study.

\section{Results}

Clinical Characteristics of the normotensive and preeclampsia samples analyzed are tabulated in Table 1. The normotensive and preeclamptic subjects selected for analysis had a significant alteration in the values of systolic and diastolic pressure during pregnancy while an insignificant change in those of systolic and diastolic pressure prior to pregnancy. There was also a significant decrease in the birth weight of fetus born to preeclamptic mother.

Figure 1 demonstrates the median values for $\mathrm{H}_{2} \mathrm{O}_{2}$-induced hemolysis of preeclamptic and normotensive cord blood RBC in comparison with $M$. purpureus and S. cerevisiae. S. cerevisiae reduced the hemolysis of $\mathrm{RBC}$ in preeclamptic condition more effectively than normotensive condition.

Tab. 2. Antioxidant status of $M$. purpureus and $S$. cerevisiae.

\begin{tabular}{|c|c|c|c|c|}
\hline Parameters & $\begin{array}{c}\text { Concentration } \\
(\mathrm{mg} / \mathrm{ml})\end{array}$ & Standard & M. purpureus & S. cerevisiae \\
\hline $\begin{array}{l}\text { DPPH. } \\
\text { (\% of } \\
\text { inhibition) }\end{array}$ & $\begin{array}{l}10 \\
20 \\
30 \\
40 \\
50\end{array}$ & $\begin{array}{l}25 \\
30 \\
36 \\
45 \\
50\end{array}$ & $\begin{array}{l}32 * \\
38 * \\
42 * \\
47 * \\
55^{*}\end{array}$ & $\begin{array}{l}26 \\
31 \\
34 \\
41 \\
47\end{array}$ \\
\hline $\begin{array}{l}\mathrm{IC}_{50} \\
\mathrm{O} 2 .- \\
\text { (\% of } \\
\text { inhibition) }\end{array}$ & $\begin{array}{l}10 \\
20 \\
30 \\
40 \\
50\end{array}$ & $\begin{array}{l}17 \\
29 \\
38 \\
48 \\
54\end{array}$ & $\begin{array}{c}43 \mathrm{mg} \\
11 * \\
25 * \\
29 * \\
42 * \\
52 *\end{array}$ & $\begin{array}{c}>50 \mathrm{mg} \\
9 \\
19 \\
24 \\
31 \\
48\end{array}$ \\
\hline $\begin{array}{l}\mathrm{IC}_{50} \\
. \mathrm{OH} \\
\text { (\% of } \\
\text { inhibition) }\end{array}$ & $\begin{array}{l}10 \\
20 \\
30 \\
40 \\
50\end{array}$ & $\begin{array}{l}14 \\
16 \\
19 \\
22 \\
27\end{array}$ & $\begin{array}{c}49 \mathrm{mg} \\
11^{*} \\
14^{*} \\
18^{*} \\
20^{*} \\
25^{*}\end{array}$ & $\begin{array}{c}>50 \mathrm{mg} \\
10 \\
12 \\
14 \\
18 \\
20\end{array}$ \\
\hline $\begin{array}{l}\mathrm{IC}_{50} \\
\mathrm{NO} . \\
\text { (\% of } \\
\text { inhibition) }\end{array}$ & $\begin{array}{l}10 \\
20 \\
30 \\
40 \\
50\end{array}$ & $\begin{array}{c}3 \\
8 \\
12 \\
20 \\
25\end{array}$ & $\begin{array}{c}20 \mathrm{mg} \\
4 \\
6 \\
7 \\
9 \\
12\end{array}$ & $\begin{array}{c}30 \mathrm{mg} \\
8^{*} \\
15^{*} \\
18^{*} \\
21^{*} \\
26^{*}\end{array}$ \\
\hline $\begin{array}{l}\mathrm{IC}_{50} \\
\text { Reducing } \\
\text { activity } \\
\text { (absorbance at } \\
\text { 700nm) }\end{array}$ & $\begin{array}{l}0.2 \\
0.4 \\
0.6 \\
0.8 \\
1.0\end{array}$ & $\begin{array}{l}0.03 \\
0.05 \\
0.08 \\
0.10 \\
0.14\end{array}$ & $\begin{array}{c}>50 \mathrm{mg} \\
0.06 \# \\
0.08 \# \\
0.10 \# \\
0.12 \# \\
0.13 \#\end{array}$ & $\begin{array}{c}49 \mathrm{mg} \\
0.04 \\
0.06 \\
0.07 \\
0.09 \\
0.11\end{array}$ \\
\hline $\begin{array}{l}\mathrm{IC}_{50} \\
\text { ABTS.+ } \\
\text { (mgs of } \\
\text { equivalence } \\
\text { of gallic acid) }\end{array}$ & $\begin{array}{c}20 \\
40 \\
60 \\
80 \\
100\end{array}$ & $\begin{array}{c}0.5 \\
0.65 \\
0.79 \\
0.98 \\
1.25\end{array}$ & $\begin{array}{c}0.3 \mathrm{mg} \\
0.48 * \\
0.51 * \\
0.69 * \\
0.96 * \\
1.17 *\end{array}$ & $\begin{array}{c}0.6 \mathrm{mg} \\
0.29 \\
0.38 \\
0.51 \\
0.74 \\
0.99\end{array}$ \\
\hline $\begin{array}{l}\mathrm{IC}_{50} \\
\text { Total phenolic } \\
\text { Content } \\
\text { (mg catechins } \\
\text { equivalent/g ) }\end{array}$ & $\begin{array}{l}10 \\
20 \\
30 \\
40 \\
50\end{array}$ & $\begin{array}{l}1.03 \\
1.11 \\
1.19 \\
1.22 \\
1.20\end{array}$ & $\begin{array}{l}57 \mathrm{mg} \\
0.98^{*} \\
1.02^{*} \\
1.05^{*} \\
1.15^{*} \\
1.18^{*}\end{array}$ & $\begin{array}{c}69 \mathrm{mg} \\
0.74 \\
0.80 \\
0.86 \\
0.98 \\
1.07\end{array}$ \\
\hline
\end{tabular}

${ }^{*} \mathrm{p}<0.001$ when compared with the standard; $\# \mathrm{p}<0.05$ when compared with the standard 
Tab. 3. Levels of glucose 6-phosphate dehydrogenase, lipid peroxide, nitrite and nitrate levels, total antioxidant capacity and catalase activity in cord blood RBCs of normotensive and preecla preeclamptic pregnant women with M. purpureus and S. cerevisiae.

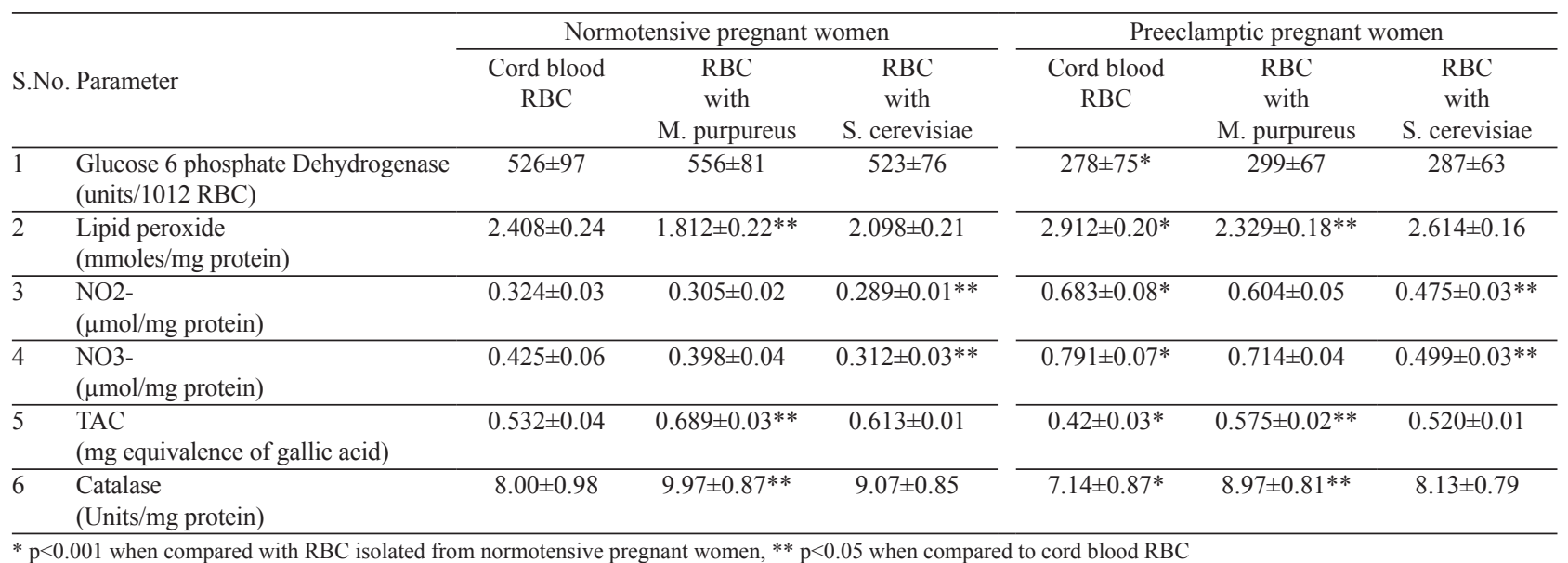

M. purpureus demonstrated a highly significant DPPH, superoxide anion, hydroxyl radical scavenging activities $(\mathrm{p}<0.001)$ compared to $S$. cerevisiae. However, $S$. cerevisiae exhibited a highly significant nitric oxide radical scavenging activity $(\mathrm{p}<0.001)$, compared to $M$. purpureus. The $\mathrm{IC}_{50}$ values of the two yeast species are demonstrated in Table 2 . The study results confirmed a significant reducing power $(\mathrm{p}<0.05)$ and a highly significant TAC (Total antioxidant capacity) activity $(\mathrm{p}<0.001)$ in extracts of $M$. purpureus when compared with those of $S$. cerevisiae. The aqueous extract of $M$. purpureus possessed higher catalase (36.67 Units / mg protein) activity compared to aqueous extract of $S$. cerevisiae (21.47 Units / mg protein). The levels of antioxidant in the aqueous extracts of $M$. purpureus and $S$. cerevisiae are shown in Table 2. The qualitative analysis demonstrated the presence of phytocomponents like flavonoids, triterpenoids, alkaloids, saponins, tannins, quinines and coumarins in the aqueous extracts of M. purpureus and S. cerevisiae.

RBCs isolated from normotensive and preeclamptic women were confirmed by analysis of RBC marker enzyme G6PDH (Glucose 6-phosphate dehydrogenase) and by microscopic analysis using Giemsa staining. There was a significant decrease in the G6PDH level in preeclamptic cord blood RBC when compared to the normotensive cord blood $\mathrm{RBC}$ as demonstrated in Table 3. Levels of LPO and nitrite/nitrate elevated significantly $(\mathrm{p}<0.05)$ in preeclamptic subjects when compared with normotensive sub-

Tab. 4. Spearman rank correlation coefficients between the normotensive and preeclamptic cord blood $\mathrm{RBC}$ with $M$. purpureus and $S$. cerevisiae.

\begin{tabular}{cccc}
\hline Variable 1 & Variable 2 & $\mathrm{r}_{\mathrm{s}}$ & $\mathrm{p}$ \\
\hline \multirow{2}{*}{ PEMP } & PESC & 0.660 & $<0.01$ \\
& NTMP & 0.614 & $<0.01$ \\
\hline \multirow{2}{*}{ NTSC } & NTMP & 0.331 & $<0.05$ \\
& PESC & 0.222 & NS
\end{tabular}

PEMP-Preeclamptic sample treated with $M$. purpureus, PESC-Preeclamptic sample treated with S. cerevisiae, NTMP - Normotensive sample treated with M. purpureus, NTSC - Normotensive sample treated with S. Cerevisiae, $\mathrm{r}_{\mathrm{s}}-$ Spearman's rho (correlation coefficient), NS - not significant jects. Similarly the TAC and catalase values showed a significant $(p<0.05)$ decrease in cord blood RBCs of preeclamptic subjects comparatively (Tab. 3). The incubation study results revealed that the activity of $M$. purpureus and $S$. cerevisiae were similar in the normotensive and preeclamptic subjects. The LPO inhibiting effect of the aqueous extract of $M$. purpureus was significantly higher than $(\mathrm{p}<0.05)$ that of aqueous extract of $S$. cerevisiae in both the samples. The nitrite/nitrate formation inhibiting effect of the aqueous extract of $S$. cerevisiae was significantly $(\mathrm{p}<0.05)$ higher than that of aqueous extract of M. purpureus in both the samples.

The correlation analysis of the anti-hemolytic activity in both the preeclamptic and normotensive samples treated with $M$. purpureus and $S$. cerevisiae is tabulated in Table 4 . There was a significant positive correlation between the preeclamptic and normotensive samples treated with M. purpureus, while there was an insignificant positive correlation between the normotensive and preeclamptic sample treated with $S$. cerevisiae, suggesting that the latter yeast species functions efficiently with increasing stress.

\section{Discussion}

Pregnancies complicated by HELLP syndrome are associated with increased materno-fetal mortality and morbidity (29). A significant increase in $\mathrm{H}_{2} \mathrm{O}_{2}$-induced hemolysis noted in preeclampsia indicates a deficient antioxidant status in preeclamptic cord blood RBC compared with normotensive cord blood RBC. Surface antioxidants in RBC like vitamin $\mathrm{C}$ can lower the $\mathrm{H}_{2} \mathrm{O}_{2}$ induced hemolysis (30). The significant positive correlation noted in normotensive and preeclamptic cord blood RBC treated with $M$. purpureus and $S$. cerevisiae suggest that both yeast species function in a similar manner to reduce the $\mathrm{H}_{2} \mathrm{O}_{2}$-induced hemolysis. The insignificant positive correlation in the normotensive and preeclamptic cord blood RBC treated with $S$. cerevisiae suggests minimal difference in the hemolytic function compared with $M$. purpureus. The percentage of hemolysis in preeclamptic sample treated with M. purpureus (23\%) and S. cerevisiae (24\%) is near to $\mathrm{H}_{2} \mathrm{O}_{2}$-induced hemolysis in normotensive sample $(25 \%)$. The 
hemolysis of RBC in preeclampsia after treatment with M. purpureus and $S$. cerevisiae are similar to that of normotensive sample (Fig. 1), indicating that both yeast species are effective in reducing the ROS-mediated hemolysis in the preeclamptic sample.

Studies have demonstrated that oxidative stress is one of the key factors in complicating preeclampsia which results in preterm birth (31). Oxidative stress is the presence of ROS in excess of the buffering capacity of available antioxidants (32). Free radicals and other damaging ROS such as superoxide anions are involved in oxidative metabolic processes; their activation is thought to increase during preeclampsia (33). Insufficient antioxidant capacity leads to oxidative stress and subsequently the oxidative injury may occur in both the maternal and placental compartments (33). The increase in oxidative stress and nitrative stress observed in cord blood RBC in this study is in coherence with the evidence observed till date, thus suggesting their significant role in the pathophysiology of preeclampsia (34). Many studies confirm that levels of antioxidants are reduced in the sera, placentas and placental mitochondria of preeclamptic women $(31,32,35,36)$. Similarly in the present study, it was noted that the antioxidant status in preeclamptic cord blood RBC was significantly decreased compared with the normotensive sample. Administration of natural antioxidants in early pregnancy may help in preventing the complication to both mother and fetus during preeclampsia (37).

Nitric oxide-mediated nitrative stress plays an important role in the pathogenesis of preeclampsia. The increase in nitrite and nitrate levels noted in cord blood RBC in this study indirectly reflects the increase in nitrative stress during preeclampsia. NO is involved in a wide range of both physiologic and pathologic events. NO can enhance ROS toxicity due to its rapid reaction to form peroxynitrite $\left(\mathrm{ONOO}^{-}\right)$. Peroxynitrite is a potentially harmful ROS as it causes nitrosylation of tyrosine residues, leading to changes in protein conformation and its inactivation. The effect of elevation in peroxynitrite, and that of reduced bioavailability of NO result from enhanced production of free radicals.

The resultant placental oxidative state may contribute to the elevation of maternal blood pressure, proteinuria, platelet dysfunction as well as levels of thromboxane and prostacyclin in preeclampsia (38). In vitro NO inhibition study results showed that $S$. cerevisiae significantly reduced the levels of nitrite and nitrate in both samples.

Our experimental results suggest that $M$. purpureus and $S$. cerevisiae possess a wide range of antioxidant activities. The evaluation of antioxidant activity of aqueous extracts of $M$. purpureus and $S$. cerevisiae revealed a highly significant DPPH radical, superoxide anion radical, hydroxyl radical and $\mathrm{ABTS}^{+}$(2, 2'-azinobis-3-ethylbenzothiozoline-6-sulphonic acid) radical cation scavenging potentials. However, M. purpureus possessed a significant reducing power whereas $S$. cerevisiae demonstrated a significant nitric oxide radical scavenging activity. Both yeast species had a significant catalase activity in normotensive and preeclamptic conditions. The aqueous extract of $M$. purpureus and $S$. cerevisiae attained the $\mathrm{IC}_{50}$ values for different scavenging assays at varying concentration compared with standard. $M$. purpureus reached $\mathrm{IC}_{50}$ at a lower concentration compared to $S$. cerevisiae in scavenging free radical whereas the $\mathrm{IC}_{50}$ value of $S$. cerevisiae in scavenging RNS was much lower than that of $M$. purpureus. Preliminary phytochemical analysis demonstrated the presence of various biologically active constituents like flavonoids, triterpenoids, alkaloids, saponins, tannins, quinines and coumarins in the aqueous extracts of both $M$. purpureus and $S$. cerevisiae.

The efficacy of $M$. purpureus and $S$. cerevisiae extracts in quenching ROS and RNS (Reactive nitrogen species) was confirmed by the inhibition of formation of LPO and nitrite/nitrate in cord blood RBC of preeclamptic and normotensive subjects. Both extracts decreased the levels of LPO and nitrite/nitrate in normotensive and preeclamptic cord blood RBC. M. purpureus was more effective in inhibiting LPO formation compared to $S$. cerevisiae. In contrast, $S$. cerevisiae exhibited a significant effect in preventing the formation of nitrite and nitrate levels in cord blood RBC of both subjects. The medicinal value of M. purpureus in various clinical conditions has been well demonstrated, while the medicinal value of $S$. cerevisiae has seldom been demonstrated. A study by Moyad et al (39) has demonstrated the usage of Epicor, a yeastbased product against common cold and flu. The latter study is the only report analyzing the medicinal property of $S$. cerevisiae. The present study is the first of its kind to demonstrate the medicinal value of both M. purpureus and S. cerevisiae under conditions of preeclamptic pregnancy.

\section{Conclusion}

This study results conclude that anti-hemolytic and antioxidant properties of S. cerevisiae which is mainly considered as nutritive yeast equal those of M. purpureus. The research work also demonstrates for the first time that diet enriched with yeasts like $M$. purpureus and $S$. cerevisiae could serve as a natural antioxidant source and good probiotic supplement for preeclamptic patients. It protects the fetus from ROS-mediated damage by stabilizing the oxidative stress-antioxidant status imbalance as well as by inhibiting ROS-mediated RBC hemolysis under such conditions.

\section{References}

1. Morris JM, Gopaul NK, Endresen MJ, Knight M, Linton EA, Dhir $\mathbf{S}$ et al. Circulating markers of oxidative stress are raised in normal pregnancy and pre-eclampsia. Br J Obstet Gynaecol 1998; 105 (11): 1195-1199.

2. Hung TH, Skepper JN, Charnock-Jones DS, Burton GJ. Hypoxia reoxygenation: a potent inducer of apoptotic changes in the human placenta and possible etiological factor in preeclampsia. Circulation 2002; 90: 1274-1281.

3. Blackwell SC, Hallak M, Hotra JW, Refuerzo J, Hassan SS, Sokol RJ, Sorokin Y. Timing of fetal nucleated red blood cell count elevation in response to acute hypoxia. Obstet Gynec Surv 2005; 60 (2): 89-91.

4. Reubinoff BE, Schenker JG. HELLP syndrome-a syndrome of hemolysis, elevated liver enzymes and low platelet count-complicating preeclampsia-eclampsia. Int J Gynecol Obstet 1991; 36: 95-102.

5. Martin SL, William B. Severe preeclampsia with persistent postpartum hemolysis and thrombocytopenia treated by plasmapheresis. Obstet Gynaec 1985; 65 (3): 53-55. 
6. Roberts JM, Redman CWG. Preeclampsia more than pregnancy induced hypertension. Lancet 1993; 342: 1447-1451.

7. Dutta DC, Konar HL. Test book of obstetrics. New Central Book Agency (P) Ltd. 2004; 222-223.

8. Madazli R, Benian A, Gumata Ket al.Lipid peroxidation and antioxidants in preeclampsia. Eur J Obstet Gynecol Reprod Biol 1999; 85 (2): 205-208.

9. Kharb S. Vitamin E and C in preeclampsia. Eur J Obstet Gynecol Reprod Biol 2000; 93 (1): 37-39.

10. Patrick L, Uzick M. Cardiovascular disease: C-reactive protein and the inflammatory disease paradigm: HMG-CoA reductase inhibitors, alphatocopherol, red yeast rice and olive oil polyphenols: A review of literature. Altern Med Rev 2001; 6 (3): 248-270.

11. Smith DJ, Olive KE. Chinese red rice-induced myopathy. South Med J 2003; 96 (12): 1265-1267.

12. Edwards CJ, Hart DJ, Spector TD. Oral statins and increased bone mineral density in post menopausal women. Lancet 2000; 355 (9222): 2218-2219.

13. Garrett IR, Gutierrez G, Mundy GR. Statins are bone formation. Curr Pharm Des 2001; 7 (8): 715-736.

14. Kohama Y, Matsumoto S, Mimura T, Tanabe N, Inada A, Nakanishi T. Isolation and identification of hypotensive principles in red-mold rice. Chem Pharm 1987; 35: 2484-2489.

15. Wood BJB. Microbiology of fermented foods Vol 2 edition Blackie academic and professional publication UK. 1998.

16. Moyad MA. Brewer's/baker's yeast (Saccharomyces cerevisiae) and preventive medicine: Part I. Urol Nurs. 2007; 27 (6): 560-561.

17. Noltmann EA, Gubler CJ, Kuby SA. Glucose 6-phosphate dehydrogenase assay. J Biol Chem 1961; 236: 1225-1230.

18. Horwitt, MKCC, Harvey GD, Duncan WC, Wilson. Effects of limited tocopherol intake in with relationships to erythrocyte hemolysis and lipid oxidations. Am J Clin Nutr 1956; 4: 408-419.

19. Beer R.F, Seizer TW. A spectrophotometric method for measuring breakdown of hydrogen peroxide by catalase. J Biol Chem 1952; 115: 130-140.

20. Viturro C, Molina M, Schmeda-Hischmann G. Free radical scavengers from Mutisisa friesiana (Asteraceae) and Sanicula graveolens (Apiacaese). Phytother Res 1999; 13: 422-424.

21. Garrat DC. The qualitative analysis of drugs. Chapman \& Hall Ltd. Jap 1964; 3: 456-458.

22. Nagai T, Sakai M, Inoue R, Inoue H, Suzuki N. Antioxidative activities of some commercially honeys, royal jelly and propolis. Food Chem 2001; 75: 237-240.

23. Halliwell B, Gutteridge JM, Aruoma OI. The deoxy ribose method: a simple 'test tube' assay for determination of rate contents for reaction of hydroxyl radicals. Anal Biochem 1987; 105: 215-219.
24. Oyaizu M. Studies on product of browning react prepared from the glucose amines. Jpn J Nutr 1986; 44: 301-315.

25. Erel O. A novel automated direct measurement method for total antioxidant capacity using a new generation, more stable ABTS radical cation. Clin Biochem 2004; 37: 277-285.

26. Chandler SF, Dodds JH. The effect of phosphate, nitrogen and sucrose on the production of phenolics and solasidine in callus of solanum laciniatum. Plant Cell Rep 1993; 2: 118-123.

27. Ohkawa H, Ohishi N, Yagi K. Assay for lipid peroxides in animal tissue with thiobarbituric acid reaction. Anal Biochem 1970; 95: 352-335.

28. Yokoi I, Habu H, Kabuto H, Mori A. Analysis of nitrite, nitrate, nitric oxide synthase activity in brain tissue by automated flow injection technique. Methods Enzymol. 1996; 268: 152-159.

29. Sibai BM, Ramadan MK, Usta I et al. Maternal morbidity and mortality in 442 pregnancies with hemolysis, elevated liver enzymes, and low platelets. Am J Obstet Gynecol 1993; 169: 1000-1006.

30. Bieri JG, Poukka RKH. In vitro hemolysis as related to rat erythrocyte content of $\alpha$-tocopherol and polyunsaturated fatty acids. J Nutr 1970; 100: 557-564.

31. Padmini E, Lavanya S, Uthra V. Preeclamptic placental stress and mitochondrial HSP70 over expression. Clin Chem Lab Med 2009; 47 (9): 1073-1080.

32. Palan PR, Mikhail MS, Romney SL. Placental and serum levels of carotenoids in pre-eclampsia. Obs Gynaec 2001; 98 (3): 459-462.

33. Harma M, Harma M, Erel O. Measurement of total antioxidant response in preeclampsia with a novel automated method. Eur J Obstet Gynecol Reprod Biol 2005; 118 (1): 47-51.

34. Adams RH, Porras A, Alonso G, Jones M, Vintersten K, Panell S et al. Essential role of p38 alpha MAP kinase in placental but not embryonic cardiovascular development. Mol Cell 2000; 6 (1): 109-116.

35. Yanik FF, Amanvermez R, Yanik A, Celik C, Kokcu A. Preeclampsia associated with increased lipid peroxidation and decreased serum vitamin E levels. Int J Gynecol Obstet 1999; 64 (1): 27-33.

36. Padmini E, Vijaya Geetha B. Placental heat shock protein 70 overexpression confers resistance against oxidative stress in Preeclampsia. Turk J Med Sci 2008; 38: 27-34.

37. Loliger J, Auroma OI, Halliwell B. The use of antioxidants in food additives. Taylor and Francis: London, 1991; 121-150.

38. Lowe DT. Nitric oxide dysfunction in the pathophysiology of preeclampsia. Nitric Oxide 2000; 4 (4): 441-458.

39. Moyad MA, Robinson LE, Zawada ET, Kittelsrud JM, Chen DG, Reeves SG, Weaver SE. Effects of a Modified Yeast Supplement on Cold/ Flu Symptoms. Urol Nurs 2008; 28: 50-55.

Received August 12, 2011. Accepted November 30, 2011. 